\title{
ABOUT THE SECONDARY POLLUTION OF WATER DURING ITS TREATMENT
}

\author{
Russkikh Ya.V., \\ Viktorovskii I.V. \\ St.Petersburg Scientific Research Center of Ecological Safety, \\ Russian Academy of Sciences, Russia
}

Keywords: water treatment; effect of "secondary water pollution"; organic microimpurities; chromato-mass-spectrometry.

In the course of water disinfection with chlorine, îzone, or fluorine organic compounds, present in initial water, undegro partial oxidation and transformation. Therefore concentration of various organic pollutants can as decrease as increase at water treatment; moreover, new compounds can be self-synthesized during this process. One of the factors responsible for such processes - high-molecular compounds - humic substances (HS) present in natural (initial) water.

Composition of organic microimpurities in water containing significant amount of HS (8 $\mathrm{mg} / \mathrm{l})$ at various stages water purification was studied by means of chromato-massspectrometry. All observed and identified compounds were divided by eight classes: 1), 2) fat acids and their esters; 3) alkanes; 4) alkenes; 5) alcohols; 6) cycloalkanes; 7) esters of phthalic acid (phthalates); 8) aromatic hydrocarbons; 9) chlorine-containing organic compounds; 10) sulfur- and nitrogen-containing organic compounds.

The obtained results testify, that traditional purification of natural water containing $8 \mathrm{mg} / \mathrm{l} \mathrm{HS}$ causes formation of the toxicologically dangerous compounds.

The problem of water quality is one of the main problems, with which human meets during his life. Already in the beginning of ÕÕ century disinfiection of water was carried out practically at all water stations. At the present time in our country the methods of water disinfection based on usage of active chlorine are the most popular. Discovered in 1974, the effiect of generation of potentially carcinogenic chlorine-containing compounds as a result of water chlorination at water stations has initiated a series of intensive toxicological, epidemiological, and medico-biological studies. Thus, the opportunity of secondary water pollution in course of water chlorination at water stations and formation of various chlorinecontaining organic compounds representing a real danger to the people, consuming this water was revealed. The further researches have shown, that this is only the part of a problem.

Natural water contains a huge number of various organic compounds - pollutants of natural and antropogenic origin. Their concentrations can be much lower than a threshold of 
detection of any modern analytical method. But after chlorination these substances are simplified and transform into a narrower circle of low-molecular compounds, which can be collect and found out in concentration close or exceeding MPK (maximum permissible concentration). The previous studies [1] have shown, that during water purification concentration of various pollutants can decrease, as well as increase, besides new compounds, not present in initial samples can be formed. One of the factors responsible fof these processes, is the presence of high-molecular connections - humic substances (HS) in natural (initial) water.

The purpose of the present work was to study a spectrum of organic microimpurities present in water at various stages of water purification, when initial water contained the appreciable amount of HS $(8 \mathrm{mg} / \mathrm{l})$.

Sample of HS was prepared using technique [3], from a soddy podzolic soil very typical for Leningrad region.

The usual circuit of water purification, used on hte Central station of "St. Petersburg Vodokanal" (fig. 1), was applied. After each stage of treatment the aliquots of water were taken and then analyzed according to GOST requirements and to the content of organic substances. Control chlorination was not carried out, because the amount of residual chlorine was rather great $(1,32-1,35 \mathrm{mg} / \mathrm{l})$.

Fig.el.

\section{The circuit of traditional water treatment}

$\underline{\text { Initial water }+\mathrm{HS}}(8 \mathrm{mg} / \mathrm{l})(\mathrm{I}) \rightarrow \underline{\text { Ammoniation and chlorination }}$ (II) $\rightarrow$

$\rightarrow$ Coagulant treatment (aluminum sulfate) (III)e $\rightarrow$

$\rightarrow$ Flocculant treatment ("Magnoflok LT-31", 4 mg/l) (IV) $\rightarrow$

$\rightarrow$ Control chlorination (V) (was'nt made in our case, because residual chlorine content was high - $1,35 \mathrm{mg} / \mathrm{l}$ )

Water treatment sampling and GOST analysis (ðÍ, color index, oxidizability, turbidity) were executed in technological laboratory of "St. Petersburg Vodokanal" (table 1).

Table 1. GOST requirements after each stage of water treatment (I - Initial watere+ HS; II - Ammoniation and chlorination; III - Coagulant treatment; IV - Flocculants treatment)

\begin{tabular}{|c|c|c|c|c|c|}
\hline \multirow{2}{*}{$\mathbf{N}$} & \multirow{2}{*}{$\begin{array}{c}\text { GOST } \\
\text { requirements }\end{array}$} & \multicolumn{4}{|c|}{ Stage of water treatment } \\
\cline { 3 - 6 } & I & II & III & IV \\
\hline 1 & Oxidizability, mg/l & $9, \mathrm{e} 2$ & $9, \mathbb{e}$ & $3, \mathrm{e}$ & 3,8 \\
\hline 2 & $\sum \tilde{\mathbf{N}}_{\text {orge } \mathrm{mg} / \mathrm{l}}$ & 1,76 & $1, \otimes 8$ & $0, \mathrm{e} 8$ & 0,23 \\
\hline 3 & ðÍ & 7,2 & 7,1 & 6,3 & 6,8 \\
\hline 4 & Color index & $8, \Theta$ & - & 4,0 & 5,2 \\
\hline
\end{tabular}

Content of organic microadmixtures was determined by the method of chromato-massspectrometry. This method is unique among other methods of ecological analytical chemistry, 
because it allows one to establish structure or its elements at the lowest concentration of compounds. Organic substances were isolated from water using extraction, following by solvent evaporation and chromato-mass-spectrometric analysis. This method of sample

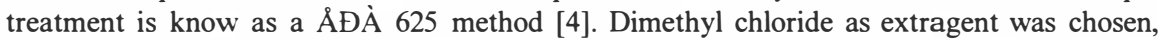
because extraction this solvent in acidic and alkaline media allows one to separate substances of various classes, moreover its low boiling temperature $\left(41^{0} \tilde{N}\right)$ permits to make repetitive solvent evaporations of sample without essential change of its composition. This way separation from water is usually applied in the majority of the circuits of the complete water analysis for pollutants. As a rule, this method is basic at the analysis of a sample of unknown composition. Besides this method allows one to receive more data, than others, and to reduce the instrument time necessary for realization of chromato-mass-spectrometric analysis and the subsequent interpretation of received mass - spectra.

The analysis of organic microadmixtures was carried out using chromato-mass-spectrometer QP-5000 ("Shimadzu" (Japan)) (capillary column "Supelco" (USA) length $60 \mathrm{~m}$, internal diameter $0,25 \mathrm{~mm}$ ). The electron ionization energy was chosen $70 \mathrm{eV}$. Scanning of mass spectra was done in a range of masses from 45 up to 450 . To identify found out compounds we applied automatic system of search from a database "Wiley", containing 140000 mass spectra. For correct determination of substances structure from mass - spectra we used ion chromatography. Quantitative analysis was carried using a method of the external standard. Calculation of substances concentrations was performed on the basis of approximation about identical sensitivity of mass-spectroscopic detector towards various classes of organic substances.

Sensitivity of the analysis was determined by a degree of extract evaporation and sensitivity of the device. Thus, we were able to identify compounds, which concentration exceed $0,1 \mathrm{mkg} / \mathrm{l}$. Besides the sample were investigated by means of UV - visible - spectrometry (UV-1601PC "Shimadzu"). Optical density of water samples was compared with distilled water, that of extracts - with dimethyl chloride.

All observed and identified compounds were divided by eight classes: 1), 2) fat acids and their esters; 3) alkanes; 4) alkenes; 5) alcohols; 6) cycloalkanes; 7) esters of phthalic acid (phthalates); 8) aromatic hydrocarbons; 9) chlorine-containing organic compounds; 10) sulfurand nitrogen-containing organic compounds (table 2).

All the classes listed, with the exception of chloroorganic compounds were found in initial water sample (with HS addition). This result proves the common opinion that HS are complex compounds containing aliphatic and aromatic components together with oxygen, nitrogen and sulfur atoms [2] (permanganate oxidizability of samples was about 9,2 $\mathrm{mg} / \mathrm{l}$ ). In this sample we have found significant amount of phthalates - substances of anthropogenic origin. They are widely used as peptizing agents and can be frequently meet in surface waters of Leningrad region.

After the first stage of water treatment (ammoniation and chlorination) the total concentration of organic substances increases (value of permanganate oxidizability grows also and attains $9,9 \mathrm{mg} / \mathrm{l}$ ). According to chromato-mass-spectroscopic analysis content of alkenes, alcohols, and, in a smaller degree, alkanes decreases, whereas various chlorine derivatives (dichloropyridines, polychlorinated alkanes, alkenes, and cycloalkanes) appear. Amount of aromatic compounds (benzoates and alkyl-benzenes), cycloalkanes (derivatives of cyclopentane and, particularly, cyclohexane) and fat acid esters increases. Content of fat acid remains practically constant. Among other compounds it is possible to note the appearance of dibutylaniline and amides, and transformation of benzothiazole and benzothiazolone into "heavier" alkyl-derivatives (for instance, methylthiobenzothiazole) and thionaphtophenoles. 
Table 2. The content of identified organic compounds for theirs classes after each stage of water treatment (I - Initial water + HS; II - Ammoniation and chlorination; III Coagulant treatment; IV - Flocculant treatment)

\begin{tabular}{|c|c|c|c|c|c|}
\hline \multirow{2}{*}{ N } & \multirow{2}{*}{ Compound name } & \multicolumn{4}{|c|}{ Stage of water treatment } \\
\cline { 3 - 6 } & & I & II & III & IV \\
\cline { 3 - 6 } & & $\mathrm{mkg} / \mathrm{l}$ & $\mathrm{mkg} / \mathrm{l}$ & $\mathrm{mkg} / \mathrm{l}$ & $\mathrm{mkg} / \mathrm{l}$ \\
\hline 2 & Fat acids & 1 & 6 & 26 & 30 \\
\hline 3 & Fat acid esters & 1 & 15 & 5 & 50 \\
\hline 4 & Alkanes & 1300 & 1150 & 20 & 50 \\
\hline 5 & Alkenes & 40 & 30 & 1 & 10 \\
\hline 6 & Alcohols & 170 & 45 & 1 & 10 \\
\hline 7 & Csters of phthalic acid (phthalates) & 130 & 130 & 20 & 10 \\
\hline 8 & Aromatic hydrocarbons & 45 & 90 & 2 & 10 \\
\hline 9 & Chlorine-containing organic & $<0,1$ & 20 & 15 & 0,2 \\
\hline 10 & compounds & & & & \\
\hline
\end{tabular}

$\sum \tilde{\mathbf{N}}_{\text {irg. }}$ - Total concentration of identified organic compounds.

Besides, various oxygen derivatives of aromatic compounds, which were not observed earlier, appear at this stage of treatment. Among them it is possible to note presence of phenol derivatives (up to $3 \mathrm{mkg} / \mathrm{l}$ ), benzothiazolone (up to $100 \mathrm{mkg} / \mathrm{l}$ ), benzofuranes $(0,5 \mathrm{mkg} / \mathrm{l})$ and methoxybenzoles $(0,5 \mathrm{mkg} / \mathrm{l})$.

After coagulant treatment (aluminum sulfate), total content of organic substances decreases considerably, that is proved by the reduction of permanganate oxidizability $(3,1 \mathrm{mg} / \mathrm{l})$. Therewith content of alkanes and cycloalkanes, alkenes and alcohols, phthalates and aromatic hydrocarbons, sulfur- and nitrogen-containing organic compounds grows considerably. The amount of chloroorganic substances and fat acid esters remains practically constant, whereas content of fat acids increases.

The flocculant ("Magnoflok LT-31") addition causes certain increase in total concentration of organic substances, that, probably, is due to the nature of the flocculant used. After this stage the content of fat acid esters increases, therewith concentration of organic acids decreases. The content of alkanes, cycloalkanes, alkenes, and alcohols also slightly increases, whereas the amount of phthalates decreases. Chloroorganic and heterocyclic (nitrogen- and sulfur-containing) compounds practically disappear. The content of residual chlorine determined according to GOST requirements was 1,32-1,35 $\mathrm{mg} / \mathrm{l}$. 
The data of chromato-mass-spectrometric analysis on content of organic substances in water samples are in a good agreement with the data of UV- spectroscopy (fig. 2).

The obtained results indicate, that presence of HS in natural water at a level of $8 \mathrm{mg} / \mathrm{l}$ causes formation of toxicologically dangerous compounds during water purification by the traditional methods. The disinfection of water with oxidizers (chlorine, îzone, fluorine) is always accompanied by the partial oxidation and transformation of organic compounds, present in water.

Fig. 2. Optical density of extracts after each stage of water treatment (I - Initial water + HS; II - Ammoniation and chlorination; III - Coagulant treatment; IV - Flocculant treatment).

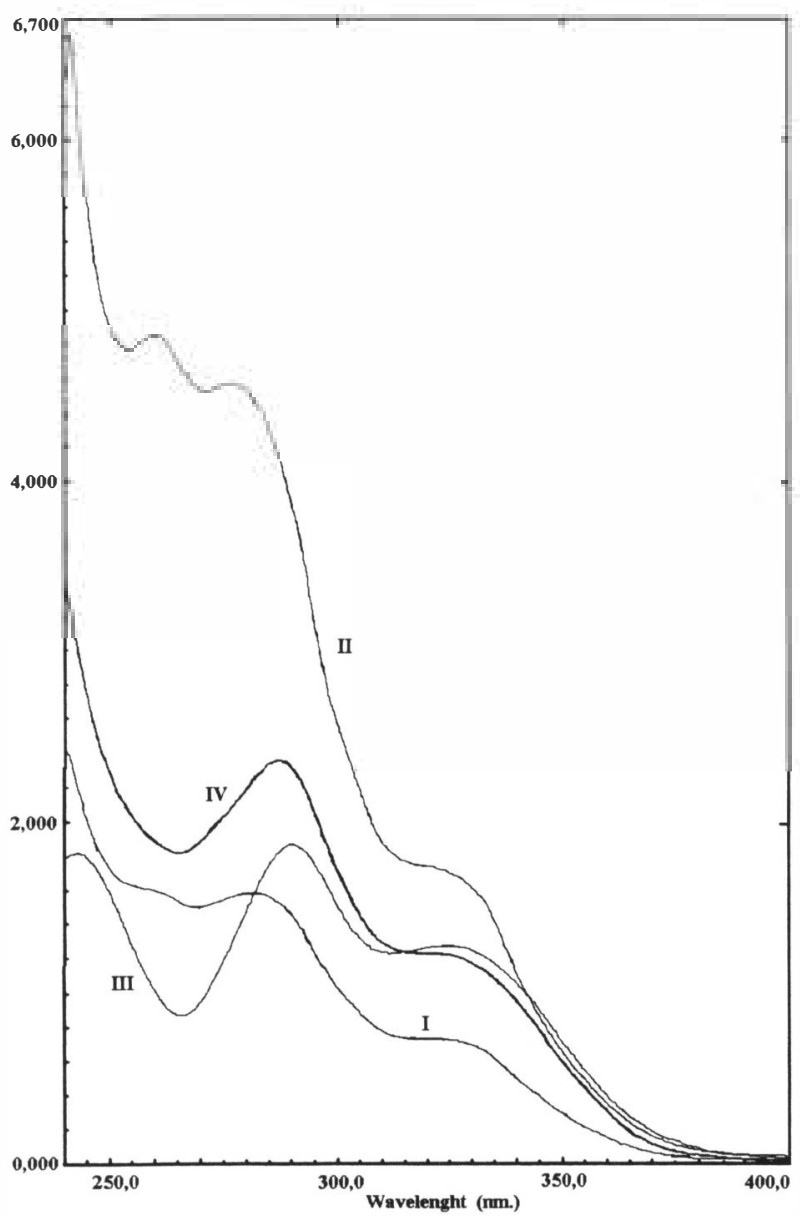


Therefore at a choice and optimization of dozes of this reactants it is necessary to take into account an opportunity of effect "of secondary water pollution" (generation of secondary organic substances - pollutants). Thus, it is necessary to control not only content of chloroorganic compounds, but also that of the other organic pollutants (first of all oxygen-containing). In expanded list of substances controlled at water purification the special attention should be paid to such classes of organic substances as: fat acids, phenols, aldehydes and phthalates. Their concentration strongly change during process of water purification, and usually one can observe tendency of their contents to increase at natural water disinfection (that, for example, is observe from table 1). This may be easily explained by the fact that during chlorination (ozonization, fluorination) various compounds, present in water are oxidized and form new, including oxygen-containing substances.

It is important to note, that the results obtained can be related only for the processes of natural water purification from organic microadmixtures (microbiological and sanitary-hygienic studies were not carried out).

Such studies seem to be undoubtedly interesting in the context of the problem of "secondary water pollution". The special attention in the subsequent researches should be paid to the influence of composition of HS present natural water on quality of drinking water. Besides it is necessary to develop express methods of analysis of natural water for the primary pollutants.

\section{References:}

1. Holodkevich S. V., Viktorovskii I. V., Zuzin I. A. (1997). Effect of generation of organic substances - pollutants at natural water disinfection in the processes of water treatment. Ecological Chemistry. 6 (4). P. 230.240.

2. Orlov D. S. (1985). Chemistry of soils. MGU (Moscow State University publishing house). pp. 287.

3. Plotnikova T. A., Orlova N. E. (1984). Usage of the modified Ponomareva Plotnikova scheme for determination of composition, nature and properties of humic substances in soils. Soil Science. N 8. P. 120-130.

4. Soniassy R., Sandra P., Schlett C. (1995). The analysis of water: organic microimpurities (practical manual). (Translation from English) St.-Petersburg. pp. 248. 